\title{
Testing Social Enterprise Models Across the World: Evidence From the "International Comparative Social Enterprise Models (ICSEM) Project"
}

\author{
Jacques Defourny', Marthe Nyssens ${ }^{2}$ iD, \\ and Olivier Brolis ${ }^{2}$
}

\begin{abstract}
In response to the large number of definitions of social enterprise (SE), various works have sought to cope with such diversity through SE typologies. Many of them are however country-specific and only very few of them are built upon solid theoretical foundations. To overcome these weaknesses, Defourny and Nyssens had put forward, in a previous article, some fundamentals for an international typology, including four SE models. The objective of the present article is to test the existence of these models on the basis of a data set covering 721 SEs and resulting from a survey carried out in 43 countries. More precisely, the statistical exploitation of the data set combined multiple factorial analysis with hierarchical cluster analysis. It appears that the existence of three of the four SE models - namely the social-business model, the social-cooperative model and the entrepreneurial nonprofit model-is strongly supported by the empirical analysis in almost all surveyed countries.
\end{abstract}

\section{Keywords}

social enterprise, third sector, models, international comparison

\footnotetext{
'University of Liège, Belgium

${ }^{2}$ UCLouvain, Belgium

Corresponding Author:

Marthe Nyssens, CIRTES/IRES, Belgium \& EMES International Research Network, UCLouvain,

3 Place Montesquieu, I348 Louvain-la-Neuve, Belgium.

Email: marthe.nyssens@uclouvain.be
} 


\section{Introduction}

Although the notions of social entrepreneurship, social entrepreneur, and social enterprise (SE) have sometimes been considered as different facets of a same phenomenon, especially in the late 1990 s and early 2000 s, the last two decades have witnessed clear trends toward distinct research developments about social entrepreneurship (and the related term of social entrepreneur) on one hand (Dacin et al., 2011 among many others) ${ }^{1}$, and social entreprise, on the contrary (Alegre et al., 2017) ${ }^{2}$ — though, of course, this does not mean that the boundaries between these two research fields are clear-cut. ${ }^{3}$ In addition to such trends, many conceptual debates are still taking place within each of both "sides," and in particular in the field of research on the SE notion, which is explicitly at the heart of this article. Various tentative definitions have been put forward, but they often increased the feeling of confusion among researchers, observers, or newcomers in the "SE field." Indeed, the lack of a shared understanding and definition of SE is today acknowledged by most researchers, and it even seems reasonable to speak of the "impossibility of reaching a unified definition of social enterprise".

In response to this conceptual diversity and sometimes confusion, various authors tried to identify categories or types of SE and to propose typologies. Although these typologies may themselves vary a lot, they provide useful lenses to grasp such diversity. However, many of these typologies are mostly inductive and country-specific and only very few are built upon solid theoretical foundations. Moreover, these analytical grids do not generally rely on systematic data collection at the enterprise level. For our part, we have developed a typology of SE models (Defourny and Nyssens, 2017) that is rooted in theoretical grounds provided by some inspiring works by Gui (1991) and Hansmann (1996) on the identity of the "third sector." The main objective of this article is to test statistically, at the enterprise level, the relevance of this typology of SE models on the basis of a large international data set resulting from a field survey carried out on more than 700 SEs in 43 countries across the world. On such basis, we put forward the hypothesis, for the purpose of this article, that this typology is neither countryspecific, nor even, more broadly, context-specific. In other words, we will try to see to what extent each SE model may be identified across countries in every world region and across regions.

This article is organized as follows. To set the ground for our analysis, we first survey existing SE typologies ("What Do Existing Typologies of SE Tell Us?") before summarizing the theoretical framework we developed in the above-mentioned paper to define a few clearly distinct SE models ("Theorizing the Diversity of SE Models"). We then present the methodology adopted for the empirical survey that is central in this article: we describe the key dimensions of SE that were captured and the methodological choices that were made for this survey, which was carried out on 721 SEs operating in various world regions. We also present the hierarchical cluster analysis (HCA) we carried out on the basis of such an outstanding data set ("Data and Method"). From there, we discuss the empirical results obtained, which provide strong support to three of the four SE models at the world level and point out some differences between regions ("Findings"). We finally conclude ("Conclusion and Avenues for Further Research"). 


\section{What Do Existing Typologies of SE Tell Us?}

The degree of market reliance is certainly a dominant criterion in the eyes of many researchers looking for a basic typology of SEs. Through his pioneering work, Dees (1996) paved the way for such an approach when he presented SEs along a singledimensional continuum between two extremes corresponding respectively to a "purely philanthropic" pole and a "purely commercial" one. However, Dees does not just refer to the market in terms of incomes from sales. Instead, he actually develops market principles (and the philanthropic principles at the other extreme) in terms of motives, value creation, methods and goals, and he argues that most SEs combine commercial and philanthropic elements in a productive balance. The major strength of Dees' SE spectrum is that the various sources of variations that he identifies pave the way for an infinite number of operational SE models. The other side of the coin is that such multiple variations along single continuous axes do not really allow for a definition of different SE categories. From the point of view of Dees' spectrum, all SEs can be seen as "intermediate organizations" and they may all be labeled as "hybrids" (Doherty et al., 2014). As for Alter (2007), she also focuses on the place and role of market logics to put forward various types of operational models, based on mission orientation, the nature of target markets and the degree of integration of business activities in social programs. In our view, this last criterion is the most original, and it has now become a classical reference: business activities can be "mission-centric" (i.e., embedded in the social mission), "mission-related" or "mission-unrelated" (i.e., just focused on earning income to financially support the social mission).

Spear et al. (2009) identified four types of SE in the United Kingdom according to their origins and development paths: mutuals, formed to meet the needs of a particular group of members through trading activities; trading charities, which develop commercial activities to fulfill their primary mission or as a secondary activity to raise funds; public-sector spin-offs, which have taken over the operation of services previously provided by the state; and new SEs, set up as new businesses by social entrepreneurs. Also in the U.K. ecosystem, Gordon (2015) considers a wider spectrum of historical origins and purposes at the organizational level; on this basis, he identifies six main SE "traditions and purposes" (mutuals, community, altruistic, ethical, private market, and public statist) each of them being characterized by a "basis," central values, primary beneficiaries, potential legal or organizational form(s), and primary income sources. Also in a country-specific perspective, McMurtry and Brouard (2015) identify five sets of SE practices that cut across the cultural and policy regime in Canada: cooperatives, market-oriented nonprofit organizations, community development/interest organizations, indigenous businesses, and businesses with a social mission.

Relying mainly on the U.S. SE landscape, Young and Lecy (2014) and Young et al. (2016) proposed the metaphor of a "social enterprise zoo," in which different types of animals seek different things, behave differently and may (or may not) interact with one another in both competitive and complementary ways. . . just like SEs, which combine social and market goals in substantially different ways. The authors propose 
"six major species of zoo animals" (each containing substantial internal variationsubspecies - as well): for-profit business corporations developing programs of corporate social responsibility (CSR), in which social goals play a strategic role; social businesses looking for an explicit balance between social impact and commercial success; social cooperatives maximizing their members' welfare while also including a general public-benefit dimension; commercial nonprofit organizations driven by their social mission; public-private partnerships; and hybrids.

These more recent typologies, which are mostly based on an inductive approach, adopt a "meso-level" perspective. They take into account that objectives and organizational features of SEs are shaped by a variety of institutions and norms - such as historical traditions, values, existing legal frameworks and discourses-within every single national context. Adopting such a meso-level perspective paves the way to identifying different models of SE in the same country.

When it comes to international comparative works, Borzaga and Defourny (2001), for the countries that then made up the European Union; Borzaga et al. (2008), for Central and Eastern Europe; and Defourny and Kim (2011), for Eastern Asia, all made attempts at international comparative analyses. Kerlin $(2013,2017)$ adopted an institutional perspective inspired by the "social origins" theory developed by Salamon et al. (2000), identifying key features of macro-institutional frameworks to suggest how any set of socioeconomic and regulatory institutions at country level tends to shape a specific major SE model per country. Kerlin's typology is rooted in a theory trying to explain the existence and the place of the nonprofit (third) sector. However, neither Kerlin's typology nor previous ones were confronted with data collected at the enterprise level.

While taking stock of these various typologies, which were inductive or/and country-specific, we now want to go one step further by providing strong theoretical foundations to explain how various "institutional logics" in the whole economy may generate different SE models.

\section{Theorizing the Diversity of SE Models}

Considering that SEs are often seen as belonging to the "third sector" or are somehow related to the latter (Defourny, 2014), we chose to build our analysis upon some of the strongest theoretical frameworks focusing on this sector's identity, such as those proposed by Gui (1991) and Hansmann (1996). Leaving aside "capital-interest-driven" or capitalist enterprises, which distribute their profits to their investors, who also control these for-profit firms, Gui (1991) defines the third sector as composed of "mutualbenefit organizations" and "public-benefit organizations." "Mutual-benefit organizations" are those in which the stakeholders (other than the investors) who have the ultimate decision-making power (the "dominant category") also make up the "beneficiary category," i.e., the category of stakeholders to whom the residual income ${ }^{4}$ is explicitly or implicitly ${ }^{5}$ distributed. Indeed, such convergence of control and benefit ensures that members' mutual interest (MI) is the objective pursued by the organization. As for "public-benefit organizations," they correspond to those in which 


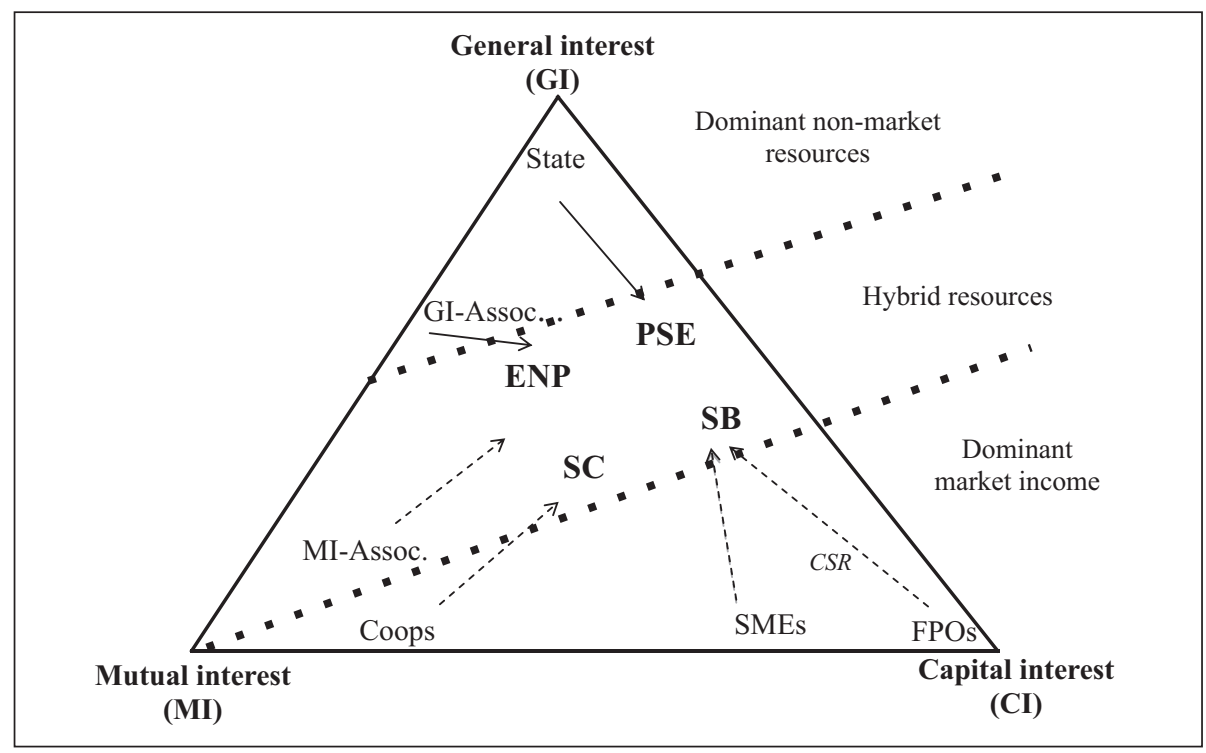

Figure I. Institutional logics and resulting SE models.

Source. Defourny and Nyssens (2017).

Note. $\mathrm{SE}=$ social enterprise; ENP = entrepreneurial nonprofit; PSE = public-sector social-enterprise; $\mathrm{SC}=$ sociadell-cooperative; $\mathrm{SB}=$ social business; $\mathrm{CSR}=$ corporate social responsibility; $\mathrm{SME}=$ small and medium enterprises; FPO = for-profit organization.

the beneficiary category is different from the dominant category: they are voluntary organizations oriented to serving other people (beneficiaries) than the stakeholders who control the organization. ${ }^{6}$ Beneficiaries are those who are at the heart of the organization's mission - more precisely, in the case of SEs, of the enterprise's social mission (Santos et al., 2015).

\section{Three "Principles of Interest" as a Cornerstone}

These distinctions lead us to consider three distinct major drivers or "principles of interest" that can be found in the overall economy: the capital interest (CI), the MI, and the general interest (GI). We propose to represent them as the vertices of a triangle in which mixes of principles can also be represented along the sides (see Figure 1).

Before locating types of SE on our graph, we note that all traditional cooperatives and associations that are seeking the interest of their members (for instance, sport clubs) are located in the "mutual-interest" angle. By contrast, those associations (voluntary organizations, charities. . .) that are seeking a public benefit as defined by Gui may be seen as located close to the general-interest angle. However, they are not in the vertex itself, as their GI (the community they serve) is usually not as wide as the one targeted by the state. On the right-hand side of the triangle, shareholder companies are located in the "capital-interest" vertex. However, when they develop CSR strategies, 
through which they tend to express a concern for some issues of GI, such concern may be represented as a limited move upward along this side of the triangle.

The figure's lower (horizontal) side represents a continuum between the cooperative treatment of profits and the capitalist stance on profits. The search for profit in a cooperative is mainly instrumental to its productive activity. Profits may only be distributed as dividends with a cap and/or put into collective reserves with an asset lock; by contrast, the main goals of shareholding companies are profit distribution and increasing the value of their shares. Many small and medium-sized enterprises, though, especially family businesses, although capitalist, may balance in a different way the search for profits and nonfinancial goals (Zellweger et al., 2013).

\section{Market Reliance and the Resource Mix as Central Issues}

Many publications and discourses on SE underline a significant move toward market activities as a key feature of SE. When trying to identify SEs, many observers suggest to look at the proportion of market income and might require that at least half of the resources come from market sales. Such a stance, however, is often far from the field reality in many countries, and it is not shared by all schools of thought (Defourny \& Nyssens, 2010). However, we fully acknowledge that market reliance is a major issue in the debate, and it is why we have drawn two dotted lines across our triangle to take into account the various combinations of resource types (market income, public grants, philanthropic resources). Let us also note that the lower dotted line divides the "mutualinterest" angle: cooperatives mainly operate on the market and they appear below this dotted line, as do all enterprises earning all or most of their income from the market; by contrast, mutual-interest associations, like leisure voluntary organizations, are located above the line, because they generally rely on a mix of market resources (membership fees, sales at a bar or cafeteria) and other resources, such as volunteering and various types of public contributions.

\section{Institutional Logics Generating SE Models}

On the basis of the various elements presented above, we tried to show how various "institutional logics" in the whole economy may generate SE models (Defourny \& Nyssens, 2017).

As shown in Figure 1, SE models (in gray) emerge from six traditional models through two distinct institutional logics:

1. The first type of logic generating social enterprises can be observed among nonprofits or public organizations experiencing a downward move toward marketization (solid-line arrows):

- The entrepreneurial nonprofit (ENP) model gathers all nonprofit organizations, most often general-interest associations (GI-Assoc.), that are developing any type of earned-income activities in support of their social mission (Fitzgerald \& Shepherd, 2018). 
- The public-sector social-enterprise (PSE) model results from a movement toward the marketization of public services which embraces "publicsector spin-offs." These social enterprises are usually launched by local public bodies, sometimes in partnership with third-sector organizations, to provide services which are outsourced (such as care services) or new services (such as those offered by work-integration social enterprises).

2. The second type of logic corresponds to an upward move of conventional cooperatives and mutual-interest associations toward a stronger general-interest orientation; such a move may also be observed through some advanced CSR initiatives launched by the traditional business world (dotted arrows):

- The social-cooperative (SC) model differs from traditional mutual-interest organizations - i.e., cooperatives (Coops) and mutual-interest associations (MI-Assoc.) — in that it combines the pursuit of its members' interests (mutual interest) with the pursuit of the interests of the whole community or of a specific group targeted by the social mission (general interest).

- The social-business (SB) model is rooted in a business model driven by shareholders' (capital) interest, but social businesses mix this logic with a "social entrepreneurial" drive aimed at the creation of a "blended value," in an effort to balance and better integrate economic and social purposes.

At first sight, when looking at Figure 1, the four SE models seem to arise from new dynamics at work in preexisting organizations. Thus, it may seem that SEs cannot be created from scratch. Such an interpretation would be clearly misleading, as a new (social) enterprise can emerge everywhere in the triangle; its location will depend on its general-interest orientation and on the way in which it balances social and economic objectives and financial resources.

As suggested above, our typology of SE models is based on some key dimensions, which we chose to name "fundamentals," but we do not pretend that it covers all possible SE cases. Especially, we are aware of the many types of hybridity that can be observed in the field. For example, partnerships between for-profits and nonprofits and those also involving local public authorities in a community-development perspective are quite common.

\section{Data and Method}

To test the relevance of this typology of SE models, we rely here on the data collected through a large survey we coordinated and which was carried out by researchers from 43 countries across the world in the framework of a broad international research project named the "International Comparative Social Enterprise Models (ICSEM) Project."

\section{The ICSEM Survey and Database}

In a first phase, all researchers involved provided a "country contribution" about the $\mathrm{SE}$ landscape in their respective countries. Among other things, researchers were 
asked to identify and characterize the various SE types they could observe. Two major distinctive features of this approach should be underlined here. First, no a priori strict definition of SE was imposed for these national contributions. We just delineated the field of analysis as "made of organizations that combine an entrepreneurial dynamic to provide services or goods with the primacy of their social aims." The emphasis was put on the embeddedness of the SE phenomenon in local contexts. Second, most research was carried out by teams rather than by individual researchers, and this fostered discussion at the local or national level, thereby reducing the risks of biases induced by purely personal perceptions.

In a second phase, to address the lack of reliable data sets at enterprise level to undertake international comparative analysis, in-depth information was collected about SEs on the basis of a common questionnaire. More precisely, ICSEM research partners interviewed the managers of three to five SEs that were deemed emblematic of each SE type identified in the project's first phase. As a result, detailed data were collected in a rather homogeneous way for 721 SEs from 43 countries (Table 1). Needless to say, such a sample is by no way representative of the SE population across the world. Indeed, not only is the distribution across continents particularly uneven, with a quasi-absence of Africa; more fundamentally, the whole SE population is simply unknown, as there is no universal definition of SE. ${ }^{7}$

These limitations do not prevent us from arguing that our overall research strategy, which combines a theoretical typology and a quite demanding bottom-up empirical approach, constitutes a significant step toward capturing the diversity of SE models. The next step was to exploit the data set built through the ICSEM survey to see if it provided any empirical support to the typology of SE models presented above.

\section{A Hierarchical Cluster Analysis to Identify Major SE Categories}

For the purpose of carrying out a cluster analysis, we extracted quantitative and qualitative (nominal and ordinal) variables from the questionnaire. The ultimate goal was to describe each of the 721 SEs along five major dimensions: (a) general identity (legal form, origin, and accreditations); (b) social mission (mission's nature, relation with the SE's main economic activity, price of the goods and services provided, and type of innovation); (c) workforce composition (workers and volunteers); (d) financial structure in general and, more precisely, ways in which the SE combines various types of resources; and (e) governance structure and rules regarding the allocation of surplus. As multiple choices and combinations of several choices were possible for many questions, we defined 141 variables.

Before undertaking a hierarchical cluster analysis (HCA) based on Ward's aggregation method, we had to solve two main issues. First, our database included both quantitative and qualitative variables, while HCA cannot be performed on qualitative variables. Second, we wanted each of the five predetermined dimensions to have the same weight, which was not the case since some dimensions were composed by a higher number of variables than others. To overcome these problems, we therefore performed a multiple factorial analysis (MFA) on the 141 defined variables and 
Table I. Number of Countries and Social Enterprises Covered by the ICSEM Survey.

\begin{tabular}{lcc}
\hline Region & Number of countries & Number of SEs \\
\hline Europe & 19 & $328(46 \%)$ \\
Asia & 9 & $100(14 \%)$ \\
Latin America & 7 & $162(22 \%)$ \\
USA, Canada, Australia, and New Zealand & 4 & $45(6 \%)$ \\
Middle East (Israel and United Arab Emirates) & 2 & $31(4 \%)$ \\
Africa (Rwanda and South Africa) & 2 & $55(8 \%)$ \\
Total & 43 & $721(100 \%)$ \\
\hline
\end{tabular}

Note. ICSEM = International Comparative Social Enterprise Models; SE $=$ social enterprise.

selected six factors. Using MFA solved our two problems: first, it made it possible to give the same importance to each of the five predetermined dimensions; second, it enabled us to describe each SE through quantitative indicators only (the SE's coordinates on each factor).

The optimal number of clusters $(n)$ resulting from the HCA corresponds to the number of clusters for which the sum of intra-cluster variances does not decrease significantly when $n+1$ clusters are considered. Based on that criterion, we first identified five clusters. Adding a supplementary cluster did not lead to a significant decrease in intra-cluster variances, but considering two extra clusters together led to a further significant decrease, which allowed us to obtain more coherent clusters. We thus finally decided to keep seven clusters.

\section{Findings}

The key results of our statistical work are displayed in Table 2, where the seven clusters are described through the various dimensions listed in the first column. The various clusters are analyzed here with the following question in mind: To what extent do these clusters confirm or not the existence of our theorized SE models?

\section{Two Clusters Indicating the Existence of a Social-Cooperative SE Model}

In two clusters among the seven (Clusters 2 and 3), a large proportion of organizations have adopted the legal form of a cooperative. This is a strong feature, which invites us to look carefully at these two clusters as potentially signaling the existence of a "cooperative-type" SE model. The presence of other legal forms than the cooperative in both clusters is not surprising, as cooperative principles can also be implemented by SEs that are not formally registered as cooperatives. For example, in developing countries, many productive activities with primary social aims operate at the local level in a cooperative way, although they do not formally register as cooperatives and remain in the informal sector. Ten percent of the organizations in Cluster 3 are indeed informal. In Cluster 2, 10\% of all organizations have adopted dedicated SE legal forms, which vary according to national legislations; some are rather close to - although technically 


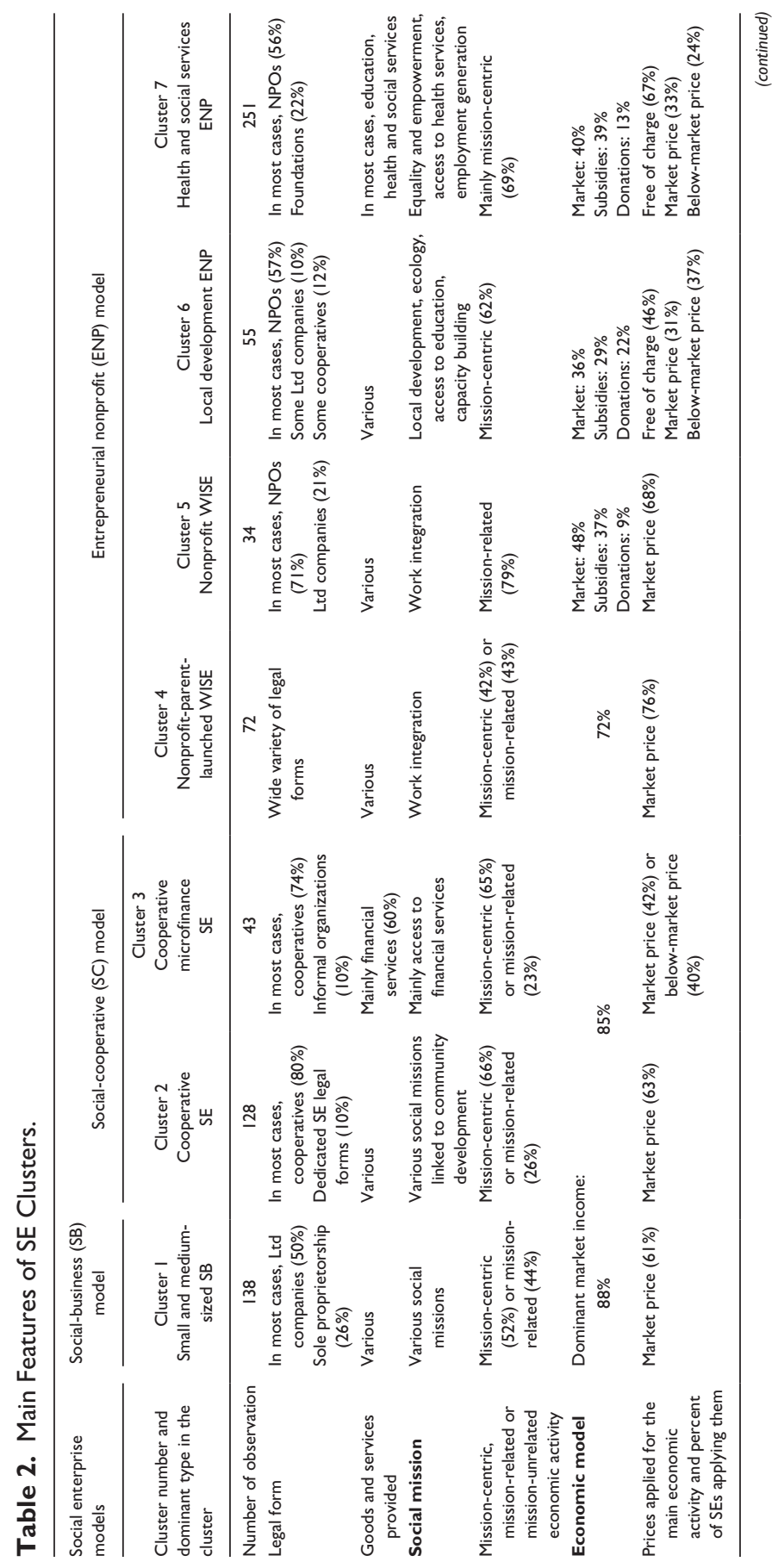




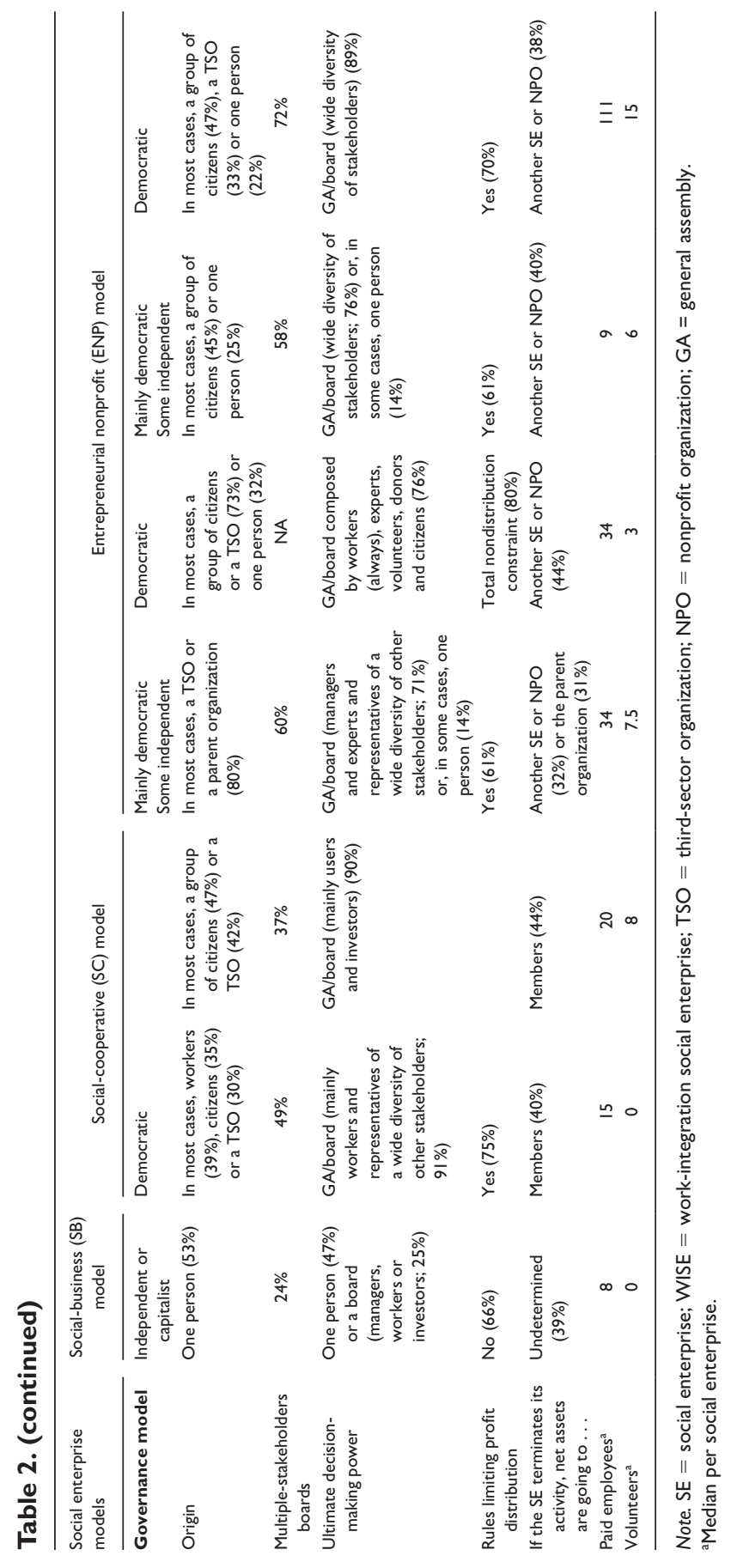


different from-the conventional cooperative status (like the "general-interest cooperative society" in France). In other cases, a label may be combined with various conventional legal forms, even though it is strongly inspired by cooperative ideals: the "social enterprise" label in South Korea provides a good example of an SE label that is particularly accessible to cooperatives.

According to our theoretical typology, the social-cooperative model may be analyzed as resulting from a move of mutual-interest organizations toward a behavior giving more importance to the GI. Such evolution can be observed at two distinct levels. First, existing conventional cooperatives and mutual-interest associations can decide to combine their mutual-interest orientation with some new activities or practices oriented toward the interest of the whole community or of a target group of nonmember beneficiaries. Second, such move can also be observed at a meso-level: in some contexts, at least part of the conventional cooperative movement, supported by social movements, can become aware of new social challenges and decide to support a new type of cooperative, i.e., the social cooperative, which appears to be best adapted to these new challenges. Such lobbying can lead to the development of a supportive ecosystem: creation of a new legal form, promotion of access to public contracts, and so on. In that regard, the development of so-called "social cooperatives" in Italy may be seen as a success story: in the late 1980s, pioneering cooperative-like initiatives were launched by groups of citizens or workers without any specific legal form; they paved the way for the subsequent development of the broader set of more formal social cooperatives. However, in many countries, public recognition has not been reached yet and "cooperative-type" SEs still operate under various, more traditional, legal forms.

There is clear evidence of the cooperative nature of Clusters 2 and 3, but we still have to document more strongly their specific "social" identity. The key question is thus the following: to what extent is it possible to distinguish organizations belonging to these two clusters from conventional cooperatives, in a way that might justify their positioning closer to the "social-cooperative" model in the above triangle?

First, let us look at the types of social mission and economic activities which might lead to qualifying organizations in these two clusters as "social enterprises" rather than as traditional cooperatives. The social mission and economic activities are clearly interwoven in the organizations making up these two clusters: two thirds of all organizations perform economic activities that are "mission-centric," and one fourth develop activities that can be qualified as "mission-related," according to Alter's (2007) classification. Although organizations in the first cooperative cluster (Cluster 2) produce a diversity of goods and services, practically all these activities are meant to serve social objectives: they aim at creating jobs for the unemployed, at generating income for poor people, at pursuing community development, at addressing ecological issues, etc. Interestingly, the second cooperative cluster (Cluster 3) does not display the same heterogeneity (and this is one of the main differences between the two clusters): some $60 \%$ of organizations in Cluster 3 provide financial and insurance services - this is why we labeled this cluster "cooperative microfinance SEs." Access to financial services has always been a main concern for 
poor populations and a central issue for a substantial component of the cooperative movement. A good deal of these cooperative initiatives were launched well before the "microfinance movement" arrived at the forefront of the social agenda; they are now fully part of it.

Second, a stronger emphasis on GI among these organizations than in traditional cooperatives could lead to governance structures involving other stakeholders than members looking for their MI. Half of the organizations belonging to the first cooperative cluster indeed display governance structures that involve a wide diversity of stakeholders (among which, in many cases, workers) in their governance. However, this is not the case in the cluster dominated by financial cooperatives where, not surprisingly, users and investors are the stakeholders most often represented.

Third, the allocation of profits as dividends on member shares might be more limited in social cooperatives than in traditional cooperatives, or it might even be prohibited. Indeed, some specific features, which are only rather rarely found in conventional cooperatives (such as a total nondistribution constraint or a strict equal distribution among members), can be observed in $50 \%$ of the organizations.

The above analysis leads us to conclude that our theorization of social cooperative as a major SE model is supported by strong empirical evidence.

\section{One Cluster Indicating the Existence of a Social-Business Model}

Cluster 1 may be identified as gathering organizations that combine a strong business orientation and a social mission, thereby indicating the existence of a "social-business" model. Before further documenting the distinctive features of this cluster, let us note a few similarities with the two cooperative-like clusters. First, data show a similar diversity of economic activities, and more or less the same diversity of social missions, in this social-business cluster and in Cluster 2 (i.e., the first of the two "cooperative-type" clusters). We also learn that organizations of both the social-business cluster and the two cooperative-type clusters mostly sell their goods and services at market prices. Finally, organizations in these three clusters operate with paid workers and they (almost) do not rely on volunteers.

Beyond these common characteristics, several other features tend to draw the picture of two quite diverging SE profiles. While "cooperative-type" SEs are set up by a group of citizens, workers or another third-sector organization, "social-business-type" SEs are most often initiated by only one person. Moreover, social businesses often adopt the legal form of limited company or sole proprietorship. As far as their activities and mission are concerned, social businesses' economic activity is more often "mission-related" which means that they more often deliver goods or services to a wider population than to the group targeted by the social mission, than that of cooperative-type SEs which tend to be, as we have seen above, more often "mission-driven."

As for the ultimate decision-making power, in organizations belonging to Cluster 1 , it most often belongs to the owner or, alternatively, to a board composed of managers, investors and/or some workers. In SEs governed by such a board, the governance can be described as "capital-interest-oriented," or even "capitalist" in some cases, while it 
might be more appropriate to speak about "independent" ownership and management when these are in the hands of a single person. This of course contrasts with the "cooperative-type" clusters, whose organizations display democratic governance structures involving a wider diversity of stakeholders.

Finally, regarding rules and provisions related to profit distribution, it is striking to note that there is no rule limiting profit distribution in $66 \%$ of organizations in the "social-business" cluster. These businesses can adopt a legal form or seek an accreditation requiring that social goals be predominant in their mission, but generally, such legal forms or accreditations (e.g., the "low-profit limited-liability company," the "flexible-purpose corporation" or the accreditation as "benefit corporation") do not impose any limit on the distribution of profit (Cooney, 2012). This is not to say, however, that all or most of the profits are usually distributed to owners: a quite common practice is to reinvest at least part of the profits in the SE.

To better capture the actual profile of SEs in the "social-business" cluster, we still need some more information, especially about their actual size. At first sight, a good deal of the social-business literature emphasizes and celebrates initiatives launched by or in partnership with multinational corporations, thereby suggesting that such initiatives tend to be rather large. The annual World Social Business Summit is emblematic of this "school of thought," which stresses four key principles: shareholders in social businesses should not expect any financial return on investment (which is easy for big corporations in the framework of a CSR strategy); all profits should be reinvested for the social mission; goods and services should be sold at low prices to reach a high number of poor people; and the absence of public subsidies should guarantee full independence from the state.

It is precisely that kind of profile we had in mind when we started to conceptualize the social-business model, but our statistical results actually suggest another picture. This cluster is made of small- and medium-sized enterprises operating on the market while pursuing a social mission at the same time. This feature is consistent with the already observed key role of an individual entrepreneur as the initiative's founder, main owner and dominant decision-maker.

As this combination of economic and social goals is implemented within less-regulated frameworks than those defined by the governance rules and structures in "cooperative-type" SEs, the balance between these goals and its evolution over time raise the question of the social mission's sustainability. For instance, only $10 \%$ of organizations in this cluster impose a reinvestment of all profits, and almost $40 \%$ have no predetermined rule about the distribution of net assets in case the activity is terminated. In such context, it seems critical to observe enterprises' actual practices more in depth: To what extent do social and/or environmental dimensions actually dominate the profit motive? Are they not mere instruments to better serve the financial interests of the owner(s)? More generally, under which conditions can a social-value-generating economic activity be considered as an expression of social entrepreneurship?

In any case, we can, at this stage, state that this cluster provides support to the idea that the social-business model is deeply rooted in small and medium enterprises' (SMEs) willingness to generate blended value. 


\section{Four Clusters Converging Toward an Entrepreneurial Nonprofit SE Model}

Among the four remaining clusters, two of them (Clusters 4 and 5) gather organizations that are mainly driven by a mission of employment generation and may therefore be considered as work-integration social enterprises (WISEs), whereas the other two clusters (Clusters 6 and 7) cover a wider spectrum of social missions.

We will first analyze the features of these two latter clusters. The dominant legal form in these clusters is that of nonprofit organization (the share of foundations is also significant in the last cluster). Other legal forms (cooperatives and commercial companies) as well as some informal organizations are also observed, but they are far fewer in number.

Organizations in Clusters 6 and 7 have been launched, in most cases, by a group of citizens, sometimes in partnership with another third-sector organization. Either the board or the GA holds the ultimate decision-making power, and this body is composed of a wide diversity of stakeholders. In some - much less frequent - cases, a single person is the SE's initiator and independently manages his or her organization. In almost $40 \%$ of SEs belonging to these two clusters, in case the activity is terminated, net assets go to another organization with a similar social mission. These features are typical of nonprofit organizations (NPOs; understood in a broad sense, including public-benefit foundations).

Services provided by organizations in Clusters 6 and 7 are mainly "mission-centric." The largest "nonprofit-type" cluster (Cluster 7) gathers organizations providing mainly education, health, and social services. Another major distinctive feature of organizations in this cluster is the fact that they are the largest organizations of the entire sample. As for Cluster 6, it gathers much smaller organizations, providing a very wide spectrum of services to foster local development, ecology, access to education, capacity building . . . These small organizations have almost as many volunteers as employees.

The "nonprofit-type" organizations belonging to these two clusters display a much wider diversity of resources than what is found in the two cooperative-type and the social-business clusters, with maximum $40 \%$ of income coming from the market. Clusters 6 and 7 gather those SEs in our sample that rely most on philanthropy, including volunteering. Only one third of these organizations sell some of their services at market price. Indeed, providing at least some services free of charge or at a price not covering most production costs is a widespread practice in these two clusters. In cases where such practice is implemented, the organization may also receive substantial public subsidies, when its production is considered to contribute significantly to the public good and cannot be financed by private (market and nonmarket) resources.

Such resource mix could be seen as somehow surprising since a usual approach to SE sees it as "a market solution to a social problem." For many scholars, however, among which those belonging to the emergence of social enterprise (EMES) school of thought (Defourny \& Nyssens, 2010), the entrepreneurial dimension of SE lies, at 
least partly, in the fact that the initiative bears a significant level of entrepreneurial risk - but not necessarily a market risk. In this broader perspective, the resource mix which can best support the social mission is likely to have a hybrid character, as it may combine trading activities with public subsidies and voluntary resources. In a similar way, Maier et al. (2016) identify several dynamics which can characterize "NPOs becoming business-like," beyond the sole market character of financial resources: NPOs can adopt business-like goals (such as commercialization or/and conversion from an NPO to an for-profit organization [FPO] legal form); they can also adopt business-like core and support processes (entrepreneurial orientation, professionalization, business-like philanthropy. . .) or develop business-like rhetoric. It is thus not surprising that many NPOs have been identified as SEs by local researchers, even though they have less than $50 \%$ of earned income.

As briefly observed above, the remaining two clusters, which have not been described so far (Clusters 4 and 5), gather mainly WISEs. The mission of WISEs is to integrate disadvantaged groups back into the labor market and society through a productive activity. In the last two decades, WISEs have been a major focus of policies promoting SE (Cooney et al., 2016; Nyssens, 2006). Initiatives in Clusters 4 and 5 sell a wide variety of goods or services, mainly at market price, and rely more heavily on earned income than organizations in Clusters 6 and 7. These enterprises' productive activities can be considered as being less often "mission-centric" and more often "mission-related" than those of enterprises in the two clusters previously analyzed: indeed, in Clusters 4 and 5, the economic activity is a means to create jobs, whatever the types of products, and these are commercialized for a population that is much wider than the group of vulnerable workers targeted by the social mission.

Most WISEs in Cluster 5 adopt the NPO legal form, and most have been launched by citizens. They share, broadly, the same type of democratic governance features than the two "entrepreneurial nonprofit" clusters analyzed before (Clusters 6 and 7).

In the other cluster bringing together WISEs (Cluster 4), legal forms are much more diverse (NPOs, foundations, limited companies, or even informal organizations), even though more than $80 \%$ of organizations in this cluster have also been launched by a parent third-sector organization or by citizens. If the SE terminates its activity, the net assets are transferred to another SE or NPO with a similar social mission or to the parent organization. The distribution of profit is fully prohibited, or profit is distributed to the nonprofit parent organization. It is why we labeled Cluster 4 "nonprofit-parentlaunched WISEs."

Although the last four clusters (Clusters 4-7) clearly suggest the existence of two major subgroups of SEs, i.e., one strongly focusing on work integration and another displaying a diversity of other social missions, all these clusters share enough features to suggest the existence of a deeply rooted "entrepreneurial nonprofit SE model," covering a spectrum of nonprofit SEs.

\section{Regional Specificities of SE Models}

Our data set also allowed us to perform a MFA, followed by a cluster analysis, on three "regional" SE subsamples, namely those of Latin America (Gaiger et al., 2019), 
Western Europe, and Central and Eastern Europe (Defourny \& Nyssens, 2021a, 2021b) ${ }^{8}$ Within each of these regions, SE patterns proved to be very similar to those emerging at the worldwide level: all three SE models identified at the global level were also clearly identified in these three regions. Across regions, however, results displayed some region-specific features for each SE model.

The cooperative type - especially worker cooperatives - constitutes the dominant SE form in Latin America. In many cases, the MI pursued by member-workers lies in the creation of jobs for these workers under their own control, but it is combined with a clear and broader social orientation, because these workers are generally living on the margins of society and working for the survival of poor families or local communities.

Although Europe displays SE patterns quite similar to the overall worldwide sample, a few distinctive characteristics are interesting to point out. In Central and Eastern Europe, after decades of mistrust in cooperatives, which were controlled by the state, the cooperative SE type is just starting to regain interest. And in this region, the importance of funds coming from EU-supported programs and projects may partly explain why the SE landscape is dominated by the nonprofit form, which appears to be the most suitable form to obtain support from EU institutions.

In Western Europe, a new wave of "citizens' cooperatives," embedded in the socialcooperative SE model, is emerging. These initiatives strive to fulfill unmet social and ecological needs and develop practices based on alternatives to economic growth as a main goal. This quite recent generation of cooperatives can be analyzed as clearly embedded in the so-called "transition movement" (Hopkins, 2013).

Finally, with regard to Asia (Bidet \& Defourny, 2019), the social-business SE model represents the largest group and displays features which are quite specific: most of these SEs are rather small social businesses, launched and managed by a single entrepreneur. However, much more should be stressed to really describe the Asian SE landscape, regarding, for instance, the influence of the diversity of religions and the legacy of communism or dictatorial regimes.

\section{Conclusion and Avenues for Further Research}

The objective of this article was to test an international typology of SE models that we had previously put forward. The first and main finding is that three of our four theoretical models are strongly supported by empirical evidence: the existence of a socialbusiness model, a social-cooperative model and an entrepreneurial nonprofit model is fully confirmed, as these models clearly emerge from the examination of the seven clusters resulting from the statistical analysis. Moreover, these three models are found in 39 countries out of 43 . So, while SEs are influenced by institutional factors at the macro level, these results show that SEs do stem from all parts of the economy and can be related to different organizational backgrounds - namely, the nonprofit, the cooperative and the business sectors - that exist in almost all countries.

Second, in contrast to the view conveyed by some influential voices highlighting SEs as market solutions to social problems, half of all surveyed SEs display hybrid financial structures, with market resources representing less than $50 \%$ of their 
financial mix. Not surprisingly, those SEs (Clusters 5, 6, and 7) generally operate under a nonprofit legal form, which enables them to mobilize more public subsidies and more philanthropic resources, including volunteering.

Third, our typology included a public or semi-public SE model, which was also mentioned by Spear et al. (2009) and by Gordon (2015) in a U.K. context characterized by public policies strongly promoting SEs. Our empirical analysis does not confirm the existence of such public-type SE model through the identification of a distinct cluster. However, in clusters gathering work-integration SEs (Clusters 4 and 5), respectively, $11 \%$ and $12 \%$ of enterprises involve a governmental agency among their founding members. A possible interpretation is that, although they do actively support SEs, most public authorities prefer to act as partners - rather than as the main entrepreneur-in the creation and management of WISEs. Another explanation for the absence of a distinct cluster confirming the existence of a public-sector SE model may be linked to the personal perception of the SE phenomenon by local researchers: many of them probably considered a priori SEs as private entities by nature, and therefore disregarded public-sector initiatives as potential SEs. Further research is clearly needed here.

We are fully aware of the limitations of the present work. Of course, the diversity of SE approaches among researchers from so many and so different contexts induced a high degree of heterogeneity in the ways SEs were identified across countries, as well as in the selection of initiatives to be covered by the survey. In the absence of a widely accepted definition of SE, we do argue, however, that our strategy enabled us to build an analytical framework encompassing a large diversity of SEs and providing some new lenses to look at such diversity. Moreover, our proposed typology of SE models was deeply rooted in theoretical grounds to explain how various institutional logics in the whole economy may generate major SE models. Last but not least, on the basis of an international data collection at the enterprise level, we demonstrated empirically that our SE-model typology is neither country-specific nor even, more broadly, context-specific, although issues related to SE ecosystems certainly deserve future research.

\section{Authors' Note}

We want to express our deep gratitude to Sophie Adam who provided an outstanding support to the whole ICSEM Project as well as to Elisabetta Severi for her help in the construction of a unique database. More broadly, we are grateful to all researchers who got involved and contributed to this ICSEM Project on a voluntary basis.

\section{Declaration of Conflicting Interests}

The author(s) declared no potential conflicts of interest with respect to the research, authorship, and/or publication of this article.

\section{Funding}

The author(s) received no financial support for the research, authorship, and/or publication of this article. 


\section{ORCID iD}

Marthe Nyssens (iD https://orcid.org/0000-0001-9138-8941

\section{Notes}

1. In their classic survey of literature on social entrepreneurship, Dacin et al. (2011) listed some 80 references, among which only one referred to social enterprise in its title.

2. On the basis of 307 documents selected because they referred to at least one of the three " SE notions » such as they understood them, Alegre et al. (2017) developed a citation map and a cluster analysis of SE definitions; they came out with five quite distinct groups, among which three focused on social entrepreneurship and a single one, quite isolated, focused on defining social enterprise.

3. Alegre et al. (2017) also identified a group where definitions of the three terms were intertwined, while Brouard and Larivet (2010) identified the components of a large number of definitions and proposed a framework to analyze the relations between the three concepts.

4. The residual income is the income that is not assigned by contract to other stakeholders than those who ultimately control the organization (Hansmann, 1996).

5. For example, through the improvement of the service delivered.

6. In such a perspective, all public (state) organizations and institutions are also typically public-benefit entities, but they form the public sector, not the third sector.

7. In a few countries where the notion of social enterprise is defined, for instance through a law, the definition does not generally enable any uncontested mapping and statistical analysis, because such a legal approach is often deemed too large or too narrow.

8. The number of surveyed SEs in Asia proved too small for the same statistical treatment but « average » SE profiles could be estimated on the basis of 100 observations.

\section{References}

Alegre, I., Kislenko, S., \& Berbegal-Mirabent, J. (2017). Organized chaos: Mapping the definitions of social entrepreneurship. Journal of Social Entrepreneurship, 8(2), 248-264.

Alter, K. (2007). Social enterprise typology. Virtue Ventures LLC.

Bidet, E., \& Defourny, J. (Eds.). (2019). Social enterprise in Asia: Theory, models and practice. Routledge.

Borzaga, C., \& Defourny, J. (Eds.). (2001). The emergence of social enterprise. Routledge.

Borzaga, C., Galera, G., \& Nogales, R. (Eds.). (2008). Social enterprise: A new model for poverty reduction and employment generation. United Nations Development Programme.

Brouard, F., \& Larivet, S. (2010). Essay of clarifications and definitions of the related concepts of social enterprise, social entrepreneur and social entrepreneurship. In A. Fayolle \& H. Matlay (Eds.), Handbook of research on social entrepreneurship (pp. 29-56). Edward Elgar.

Cooney, K. (2012). Mission control: Examining the institutionalization of new legal forms of social enterprise in different strategic action fields. In B. Gidron \& Y. Hasenfeld (Eds.), Social enterprises: An organizational perspective (pp. 198-221). Palgrave Macmillan.

Cooney, K., Nyssens, M., O’Shaughnessy, M., \& Defourny, J. (2016). Public policies and work integration social enterprises: The challenge of institutionalization in a neoliberal era. Nonprofit Policy Forum, 7(4), 435-460.

Dacin, M. T., Dacin, P. A., \& Tracey, P. (2011). Social entrepreneurship: A critique and future directions. Organization Science, 22(5), 1203-1213. 
Dees, J. G. (1996). The social enterprise spectrum: Philanthropy to commerce. Harvard Business School, Publishing Division.

Defourny, J. (2014). From third sector to social enterprise: A European research trajectory. In J. Defourny, L. Hulgård, \& V. Pestoff (Eds.), Social enterprise and the third sector (pp. 17-41). Routledge.

Defourny, J., \& Kim, S.-Y. (2011). Emerging models of social enterprise in Eastern Asia: A cross-country analysis. Social Enterprise Journal, 7(1), 86-111.

Defourny, J., \& Nyssens, M. (2010). Conceptions of social enterprise and social entrepreneurship in Europe and the United States: Convergences and divergences. Journal of Social Entrepreneurship, 1(1), 32-53.

Defourny, J., \& Nyssens, M. (2017). Fundamentals for an international typology of social enterprise models. Voluntas, 28(6), 2469-2497.

Defourny, J., \& Nyssens, M. (Eds.). (2021a). Social enterprise in Central and Eastern Europe: Theory, models and practice. Routledge.

Defourny, J., \& Nyssens, M. (Eds.). (2021b). Social enterprise in Western Europe: Theory, models and practice. Routledge.

Doherty, B., Haugh, H., \& Lyon, F. (2014). Social enterprises as hybrid organizations: A review and research agenda. International Journal of Management Reviews, 16(4), 417-436.

Fitzgerald, T., \& Shepherd, D. (2018). Emerging structures for social enterprises within nonprofits: An institutional logics perspective. Nonprofit and Voluntary Sector Quarterly, 47(3), 474-492.

Gaiger, L. I., Nyssens, M., \& Wanderley, F. (Eds.). (2019). Social enterprise in Latin America: Theory, models and practice. Routledge.

Gordon, M. (2015). A typology of social enterprise "traditions" (ICSEM Working Papers No. 18). The International Comparative Social Enterprise Models (ICSEM) Project.

Gui, B. (1991). The economic rationale for the "third sector." Annals of Public and Cooperative Economics, 62(4), 551-572.

Hansmann, H. (1996). The ownership of enterprise. Harvard University Press.

Hopkins, R. (2013). The power of just doing stuff: How local action can change the world. Green Books.

Kerlin, J. A. (2013). Defining social enterprise across different contexts: A conceptual framework based on institutional factors. Nonprofit and Voluntary Sector Quarterly, 12(1), 84108.

Kerlin, J. A. (Ed.). (2017). Shaping social enterprise: Understanding institutional context and influence. Emerald Group.

Maier, F., Meyer, M., \& Steinbereithner, M. (2016). Nonprofit organizations becoming business-like: A systematic review. Nonprofit and Voluntary Sector Quarterly, 45(1), 64-86.

McMurtry, J. J., \& Brouard, F. (2015). Social enterprises in Canada: An introduction. Canadian Journal of Nonprofit and Social Economy Research, 6(1), 6-17.

Nyssens, M. (Ed.). (2006). Social enterprise: At the crossroads of market, public policies and civil society. Routledge.

Salamon, L., Sokolowski, W., \& Anheier, H. (2000, December). Social origins of civil society: An overview (Working Paper of the Johns Hopkins Comparative Nonprofit Sector Project, No. 38). Johns Hopkins Center for Civil Society Studies.

Santos, F., Pache, A.-C., \& Birkholz, C. (2015). Making hybrids work: Aligning business models and organizational design for social enterprises. California Management Review, 57(3), $36-58$. 
Spear, R., Cornforth, C., \& Aiken, M. (2009). The governance challenges of social enterprises: Evidence from a UK empirical study. Annals of Public and Cooperative Economics, 80(2), 247-273.

Young, D., \& Lecy, J. D. (2014). Defining the universe of social enterprise: Competing metaphors. Voluntas, 25(5), 1307-1332.

Young, D., Searing, E., \& Brewer, C. (Eds.). (2016). The social enterprise zoo. Edward Elgar.

Zellweger, T. M., Nason, R. S., Nordqvist, M., \& Brush, C. G. (2013). Why do family firms strive for nonfinancial goals? An organizational identity perspective. Entrepreneurship Theory and Practice, 37(2), 229-248.

\section{Author Biographies}

Jacques Defourny is Professor Emeritus at the Centre for Social Economy, HEC Management School of the University of Liege (Belgium). He was the first president of the EMES network.

Marthe Nyssens is a full professor at the School of Economics of the Catholic University of Louvain (UCLouvain, Belgium) and a member of the Interdisciplinary Research Center on Work, State and Society (CIRTES, UCLouvain). She is the current president of the EMES network.

Olivier Brolis holds a $\mathrm{PhD}$ in Economics and Management Science. He is a lecturer at FOPES and researcher associated with the CIRTES (UCLouvain, Belgium). 